\title{
Marcel Proust e as Reminiscências de um Mau Aluno
}

Elisabete Zardo Búrigo ${ }^{1}$

\begin{abstract}
Resumo: O trabalho apresenta representações da educação escolar presentes no romance "Em busca do tempo perdido", de Marcel Proust, e identifica nelas traços da escolarização do autor. Os excertos que fazem menção à escola ou a saberes matemáticos são extraídos a partir de edição brasileira e de versão francesa da obra, cotejados com documentos escolares, e analisados à luz do conceito de aculturação escolar, tal como é descrito por Chervel. As Álgebras e Geometrias reinventadas pelo narrador do romance são interpretadas como construções literárias através das quais o autor evoca, em um movimento simultâneo de transgressão e de homenagem, a educação matemática escolar de sua juventude.
\end{abstract}

Palavras-chave: História e literatura; História da educação; Educação matemática; Disciplinas escolares.

\section{Marcel Proust and the reminiscences of a bad student}

\begin{abstract}
The work presents representations of education and some of the author's school education imprints present in the novel "In Search of Lost Time" by Marcel Proust. The excerpts that mention the school or mathematical knowledge are extracted from a Brazilian edition and a French version of the work. School documents are also looked upon. The analysis takes into account the concept of school acculturation, as described by Chervel. The algebras and geometries invented by the narrator of the novel are interpreted as literary constructions through which the author evokes, in a simultaneous movement of transgression and honor, school mathematics education of his youth.
\end{abstract}

Keywords: History and litterature; History of education; Mathematical education; School disciplines.

\section{Introdução}

O que a literatura tem a nos dizer sobre a educação e, em particular, sobre a educação matemática? No rastro da História Cultural, a História da Educação, em especial desde os anos 1990, tem tomado a literatura ficcional como fonte de indícios sobre práticas escolares do passado e sobre as representações da educação escolar correntes ao tempo da produção da obra literária (Pesavento, 2000, 2004; Lopes, 1998; Xavier, 2008).

1 Doutora em Educação e licenciada em Matemática, docente do Programa de Pós-Graduação em Ensino de Matemática e do Instituto de Matemática e Estatística da Universidade Federal do Rio Grande do Sul. 
Os romances "Ateneu", de Raul Pompeia, e "The catcher in the rye" [O apanhador nos campos de centeio], de John Salinger, são exemplos de textos densos em referências à instituição escolar. $\mathrm{O}$ caráter confessional dessas obras permite que, assim como as escritas biográficas discutidas por Gomes (2012), possam ser tomadas como testemunhos de práticas escolares comuns à época da juventude de seus autores.

Mas em sociedades escolarizadas, como é o caso dos centros urbanos europeus ou, mesmo, latino-americanos do século XX, as referências à educação escolar não estão circunscritas aos textos que tomam a escola como cenário, ou que têm professores e alunos como protagonistas. O percurso escolar é componente dos processos de construção dos personagens, e saberes escolares se fazem inevitavelmente presentes pelas suas vozes ou pela voz do próprio narrador.

Tal é o caso do romance "À la recherche du temps perdu" [Em busca do tempo perdido], a principal obra ficcional do escritor, ensaísta e crítico literário Marcel Proust, que viveu em Paris de 1871 a 1922. No romance, reminiscências, invenções, deformações e deslocamentos compõem um emaranhado impregnado da intenção literária. É em meio a esse emaranhado que podemos identificar as representações do autor sobre a escola e seus saberes e, a partir delas, rastrear traços de sua própria educação escolar. Pois, como lembra Haiduke (2009), por maior que seja a ambição do escritor de se separar do mundo, ele está inserido em um campo literário e em uma realidade social, e "ele cria com aquilo [de] que dispõe” (Ibid., p. 18).

\section{A escola evocada em "À la recherche du temps perdu"}

O romance "Em busca do tempo perdido", produzido entre 1909 e 1922, tem o formato de relato autobiográfico, apresentado pelo narrador segundo um cruzamento de temporalidades - a do fluxo de suas "memórias involuntárias" e a do tempo cronológico, rememorado, desde a infância. As reminiscências do narrador tendem a se confundir com as de Proust. Esse efeito ilusionista é intencionalmente provocado pelo autor, que empresta ao personagem o nome Marcel e vários elementos de sua própria trajetória - a origem burguesa, a vida passada em Paris entre o final do século XIX e início do século XX, a frequência ao Liceu, o desejo de tornar-se escritor.

Ao mesmo tempo em que enfatiza a subjetividade através da qual percebemos o mundo, a obra inscreve-se na tradição do romance realista.

A acuidade com que retratou a sua época valeu a Proust ser considerado, por muitos de seus contemporâneos, como historiador da III República Francesa (Haiduke, 2013). Segundo Walter Benjamin, "no que diz respeito ao século XIX, não foi Zola nem Anatole France, mas o jovem Proust, o esnobe sem importância, o 
perturbado frequentador de salões, quem capturou as mais incríveis confissões de uma época agonizante" (Benjamin, 2010, p. 32).

O tom predominante, no texto, é o do desencanto. Para Coutinho (2005), o clima retratado por Proust é o do fim da crença no progresso engendrado pelo capitalismo, em um contexto de crise e de acirramento das disputas imperialistas, que culminariam na eclosão da Grande Guerra. Haiduke (2009) menciona também a derrota na Guerra Franco-Prussiana, em 1871, como catalisadora de um sentimento de decadência francesa e de busca de uma regeneração pelo nacionalismo, que se expressou na disseminação do antissemitismo, de um lado, mas também no antigermanismo e no apelo por uma arte patriótica. Os debates veiculados pela imprensa da época - o caso Dreyfus, a rivalidade com a Alemanha, as recomposições dos ministérios - ecoam no romance, nas conversações entre os frequentadores dos salões parisienses em que o narrador circulava.

A instituição, nos anos 1880, do ensino primário laico, gratuito e obrigatório, dos seis aos treze anos, pode ser compreendida como componente da mesma lógica nacionalista, pois tratava-se, segundo o Ministro Jules Ferry, de constituir o "Estado educador e fiscalizador" (Kahn, 2010).

Esse tema, contudo, está quase que ausente do romance. Ele aparece em uma alusão irônica e desdenhosa do Duque de Guermantes, que, ao ensino universalizado, contrapõe os clubes de acesso restrito à aristocracia de nascimento e seus convidados: "Eu, que não tenho a honra de fazer parte do ministério da Instrução Pública, [...] nem do Clube Volney (pertenço apenas ao União e ao Jockey)...” (ETP32, p. 213).

No mais, a instituição escolar não compõe os temas em debate, nem é cenário da narrativa. Nas reminiscências alusivas à infância e à juventude do narrador, as menções à experiência escolar também são vagas e esparsas. Esse silêncio é interpretado por Tadié (1996) como um esquecimento do autor, talvez intencional:

Resultados escolares adequados, desiguais, mas não brilhantes, confirmam que a carreira escolar não se confunde com a literária: os mais belos versos não são os do primeiro da classe, mas os dos excêntricos, aqueles que não escrevem nem Le petit chose, nem Le livre de mon ami, nem Le roman d'un enfant. Para eles, o liceu cai no esquecimento. (Tadié, 1996, p. 167-168, nossa tradução).

Nossa interpretação diverge parcialmente da de Tadié: o liceu não foi esquecido, e as marcas do ensino secundário no pensamento de Proust não se circunscrevem à

2 Como será explicado adiante, designamos por ETP (Em busca do tempo perdido) a versão brasileira da obra de Proust utilizada para a elaboração deste texto. 
cultura literária e filosófica. Pois encontramos, dispersa na narrativa, uma profusão de alusões a saberes e práticas escolares, inclusive saberes matemáticos, nas quais podemos identificar representações da escola e traços da educação escolar de Proust.

Essas referências à escola e à educação matemática escolar são o objeto deste estudo.

\section{A leitura do romance segundo a perspectiva da aculturação escolar}

As disciplinas escolares, conforme nos alerta Chervel (1990), não correspondem apenas a compartimentações dos conteúdos ou dos temas que se espera que sejam abordados na educação escolar. Sua institucionalização também não pode ser compreendida apenas como popularização do conhecimento produzido pela pesquisa acadêmica. As disciplinas escolares têm vida própria e correspondem a finalidades específicas da educação escolar. Dentre essas finalidades, o autor destaca a de disciplinamento do pensamento. Aprendemos, na escola, a adotar um determinado vocabulário e estilo, a reconhecer determinados tipos de fontes, argumentos e procedimentos como válidos, e a rejeitar outros. Aprendemos, por exemplo, que a Álgebra envolve resoluções de equações e que, para calcular áreas de figuras, precisamos conhecer as fórmulas correspondentes. Esses efeitos disciplinadores da educação escolar seriam muito mais persistentes e duradouros do que a aprendizagem de determinados conteúdos, pretensamente avaliados nas provas.

Os processos através dos quais nossos modos de falar, ler e pensar são configurados pela escola são referidos por Chervel (1990) como "aculturação escolar". O autor argumenta sobre a importância de se investigar essa "aculturação", entre sujeitos adultos que já deixaram a escola. Esses estudos nos permitiriam compreender melhor os efeitos, a médio e longo prazo, da escolarização.

O que lembramos, o que sabemos, ou como somos marcados por tudo aquilo que estudamos?

A questão suscita várias dificuldades metodológicas. De um lado, porque é difícil, senão impossível, distinguir, nos processos de escolarização, aquilo que é comum e aquilo que é singular nos percursos dos sujeitos que foram, um dia, estudantes. De outro lado, porque às experiências de escolarização se sobrepõem muitas outras, vividas na juventude e na idade adulta, que produzem emaranhados de saberes e modos de pensar nos quais, novamente, é difícil distinguir aquilo que foi aprendido na escola ou fora dela.

No estudo dos efeitos mais persistentes ou perenes da escolarização, pensamos que as escritas autobiográficas de sujeitos escolarizados podem se constituir em 
fontes relevantes, pois, como argumenta Gomes (2012), esses textos nos dão acesso ao modo como as experiências escolares são lembradas e representadas pelos seus autores.

No texto ficcional, o autor não assume, como no texto autobiográfico, o compromisso de "contar diretamente sua vida (ou uma parte, ou um aspecto de sua vida) com um espírito de verdade" (Gomes, 2012, p. 122). Mas as memórias do autor também participam da produção do texto, em particular na tradição do romance realista, em que está presente a preocupação com a verossimilhança da trama narrada.

Toda memória é reconstrução: "uma urdidura lenta e caprichosa, cheia de lacunas e silêncios preenchidos ou então desconsiderados, que são compostos com outros tantos detalhes, em cruzamentos e correspondências que se renovam" (Pesavento, 2000, p. 48).

A evocação do passado é mediada pelas representações do mundo social e da escola: aquelas em circulação ao tempo da escrita, e que impregnam os modos de pensar do autor, ou com as quais ele se debate. Referimo-nos aqui às representações, interiorizadas ou materializadas, como os efeitos da articulação entre os movimentos de fazer "presente aquilo que está ausente" e de "se apresentar representando algo" (Chartier, 2011, p. 18-19).

Através dos traços de memória, portanto, não pretendemos aceder diretamente à experiência escolar do autor, tal como foi vivida em sua juventude; mas ao modo como ela foi lembrada e representada muitos anos mais tarde.

Os excertos aqui reproduzidos e analisados, considerados representativos das alusões feitas, na obra, à escola e aos saberes matemáticos, foram identificados a partir da leitura da edição em português do romance "Em busca do tempo perdido", revisada por Olgária Chaim Féres Matos, Pierre Clémens e Maria Lúcia Machado, publicada entre os anos de 1992 e 1999 pela Editora Globo, em sete volumes. A partir deles, foram buscados os trechos correspondentes na versão francesa publicada pela Editora Gallimard, em 1999, em um único volume³ , sob a direção de Jean-Yves Tadié. A versão francesa será referida neste texto como RTP; a versão brasileira será referida com a sigla ETP, seguida do número correspondente ao volume consultado. Ao reproduzir as duas versões, oferecemos ao leitor a possibilidade de avaliar a propriedade da tradução de cada trecho para o português, e nos abstemos de fazê-lo.

3 É importante registrar que não nos referimos à "versão original" do romance, pois sabemos, da correspondência com o editor Gaston Gallimard, que entre os textos ditados, datilografados, enviados aos tipógrafos, revisados e modificados por Proust e, finalmente, publicados, produziram-se muitas versões. 
Na leitura dos excertos, tomamos em conta escritos sobre o ensino secundário francês do final do século XIX ${ }^{4}$, e outros documentos, dentre os quais destacamos os boletins escolares citados por Ferré (1959). Através desses boletins, sabemos que Proust era considerado, por seus professores de Matemática, um aluno fraco e desatento. Ao identificar e analisar as representações da escola e dos saberes matemáticos, para além da discussão sobre Proust, suas reminiscências e obra literária, buscamos, então, provocar uma reflexão sobre sobre os modos como somos marcados, mesmo quando já não estamos obrigados a realizar exercícios e exames, pelas disciplinas escolares que não escolhemos estudar.

\section{O ensino secundário ao tempo de Proust}

O ensino secundário francês, ao tempo de Proust, era ministrado nos liceus, criados por Bonaparte a partir de 1802, como componentes de um sistema escolar estatal, e em substituição aos antigos colégios mantidos pelas congregações religiosas e às escolas centrais, criações do período revoluconário. Destinado à formação das elites, o ensino secundário ainda era, nas últimas décadas do século XIX, pago, basicamente masculino, frequentado por cerca de 3\% dos jovens do grupo etário correspondente (Belhoste, 1990). Os liceus mantinham suas próprias classes iniciais, preparatórias ao ensino secundário, e constituíam, assim, uma ordem apartada do ensino primário, gratuito e acessível às camadas populares.

Recrutados entre os filhos dos notáveis, os estudantes dos liceus tinham como destino natural a burocracia de Estado, as forças armadas, a diplomacia, a magistratura, o professorado, e as carreiras liberais, notadamente o Direito e a Medicina. A ambição do ensino secundário, segundo Belhoste (1990), era a de formar homens cultos, mais do que a de ensinar conhecimentos úteis:

O ensino secundário francês, dizia-se por toda parte, extrai sua virtude educativa de seu caráter universal e desinteressado. Colocando o aluno, permanentemente, em contato com os ideais mais elevados, pretende nele inculcar uma alta ideia de seus deveres e prepará-lo moral e intelectualmente a ocupar as posições superiores da sociedade. Posteriormente, numa faculdade ou numa grand école, ele receberá a educação especial indispensável para abraçar uma carreira (Belhoste, 1990, p. 374, nossa tradução)

4 Recorremos especialmente a Belhoste (1990) e a Gispert e Hulin (2000) porque tratam do currículo - na sua acepção ampla - do ensino secundário nesse período. Um amplo panorama do ensino secundário francês no século XIX pode ser encontrado em: Jacquet-Francillon, d'Enfert e Loeffel (2010); Caspard, Luc e Savoie (2005); Hulin (2007). 
No currículo, herdeiro da tradição clássico-humanista, a matemática e as ciências físicas ocupavam um lugar menor, com finalidades mal definidas, oscilando entre uma visão mais utilitarista e outra centrada no enfoque dedutivo (Gispert \& Hulin, 2000). Segundo Belhoste (1990), no ensino secundário clássico5 ${ }^{5}$ a Matemática ocupava, da sixième à réthorique, apenas uma a três horas semanais em vinte, e a Físico-Química era estudada apenas na classe terminale, preparatória ao baccalaurèat. As ciências naturais eram mais valorizadas; tiveram seu peso ampliado pela reforma de $1880^{6}$, e eram ensinadas desde a classe cinquième.

A geometria estudada era a euclidiana, revisada por Legendre, e o raciocínio geométrico era, segundo Belhoste (1990), o único tipo de raciocínio rigoroso proposto aos alunos, o que tornava decisiva a sua influência sobre todo o ensino científico:

Quaisquer que sejam os inconvenientes de um ensino excessivamente abstrato e formal, fora do alcance da maioria dos alunos, o respeito superticioso pelos Antigos, que impregna a cultura do secundário, parece interditar toda contestação séria. Charles Méray denuncia desde muito tempo a geometria elementar do collége, "semelhante a esses maníacos cujas casas, entulhadas de velharias remendadas, são mostradas a todos os visitantes, conservadas e manejadas como joias de valor", e que "pensam causar boa impressão ao lidar com objetos infantis desbotados após vinte séculos”. Méray, entretanto, permanece isolado, como um excêntrico (Belhoste, 1990, p. 380, nossa tradução).

A aritmética, a álgebra e a trigonometria,

[...] ensinadas mais ou menos como ao tempo de Lacroix, ficam empalidecidas. Mal articuladas, sem concepções ou métodos de conjunto, oferecem uma exposição desconectada, misturando o útil e o acessório, o geral e o particular, favorecendo a "decoreba" por parte dos alunos. (Belhoste, 1990, p. 380, nossa tradução).

Esse ordenamento do ensino secundário sofreria uma ampla reforma no início do século XX. Uma enquete sobre as finalidades e o caráter do ensino secundário, lançada por uma comissão parlamentar em 1898, ganhou contornos de um debate nacional. A reforma, decretada em 1902, elevava o ensino das "humanidades científicas" ao mesmo patamar das "humanidades literárias". A matemática, segundo o ponto de vista dos reformadores, deveria assumir agora um caráter experimental, e o

5 Em 1865 foi estabelecido na França um ensino secundário especial, sem o ensino do latim e do grego, com ênfase no ensino científico e técnico. Em 1880 foi criado, através da Lei Camille Sée, o ensino secundário para moças. O ensino secundário clássico distinguia-se de ambos pelo currículo clássico-humanista que preparava para o exame baccalaurèat (Jacquet-Francillon, D’Enfert \& Loeffel, 2010).

6 Os programas do ensino secundário clássico foram reformados por decreto de 2 de agosto de 1880. 
raciocínio indutivo, tendo como ponto de partida a experiência dos alunos, ganhava legitimidade (Belhoste, 1990).

\section{Os anos de liceu de Marcel Proust}

Sabemos, de Ferré (1959), que Proust frequentou o Lycée Condorcet desde outubro de 1882, quando ingressou na classe cinquième com 11 anos, até a classe de Philosophie, em $1889^{7}$. Devido a uma doença respiratória crônica, a frequência ao liceu era irregular; por esse motivo repetiu a classe seconde, no ano escolar 1886-87 (Ferré, 1959, p. 123).

Apesar dessa irregularidade, ele teve um desempenho escolar destacado nas disciplinas literárias - francês, grego e latim -, como se poderia imaginar, mas também nas disciplinas de História e de Ciências Naturais, pelas quais mostrou, na escola e, mais tarde, nos seus textos literários, persistente interesse ${ }^{8}$. O liceu, foi ainda, lugar de iniciação aos debates literários e à publicação em revistas criadas pelos próprios estudantes, como a Lundi, a Revue de Seconde, a Revue verte a Revue Lilas (Tadié, 1996).

As apreciações dos professores de Matemática, por outro lado, indicavam um desempenho reiteradamente fraco, ou aquém do esperado.

Nos boletins do liceu, os professores anotavam, a cada trimestre e para cada disciplina, uma apreciação abreviada para a conduta, para a application [esforço] e o progresso; havia uma coluna separada para outras observações. Em escala descendente, as apreciações eram TB (très bien ou muito bem), B (bien ou bem), AB (assez bien ou suficiente), "pas" (passable ou regular) e "méd" (medíocre ou fraco).

Na quatrième, o professor de matemática anota "passable" para o progresso de Marcel, em todos os trimestres; na troisième, as apreciações são B (Ferré, 1959, p. 110). Na classe seconde, as apreciações para o esforço e o progresso são apenas "passable"; ao final do ano, o professor Brichet anota que Marcel "não trabalha", é um aluno "fraco" (Ibid., p. 148). O desinteresse pela matemática é atestado em comentário sobre uma redação do colega Daniel Halévy, redigido “muito rapidamente, durante a correção de

7 No sistema escolar francês, as classes do ensino secundário são denominadas segundo a ordem de seu adiantamento e, portanto, inversa à usual no Brasil. As classes sixième, cinquième, quatrième e troisième, cursadas nesta ordem, compõem o primeiro ciclo do secundário, comumente referido como collège. O nome lycée é usado para designar o segundo ciclo e os estabelecimentos que o oferecem. O lycée tem início com a seconde; ao tempo de Proust, a seconde era seguida da rhétorique, nome herdado da tradição dos colégios jesuítas, em que o estudo da Retórica sucedia o estudo da Gramática e as Humanidades; após a rhétorique, vem a classe terminale, com suas diferentes vertentes, dentre as quais a de Philosophie.

8 Em Ciências Naturais obteve, ao final do cinquième, o segundo prêmio e, ao final da quatriéme, uma menção honrosa. Na classe seconde, obteve o segundo prêmio de História. Em redação, obteve vários prêmios, inclusive o primeiro prêmio de honra, ao final da classe terminale. 
um problema" (Ibid., p. 145). Na classe rhétorique, cursada em 1887-1888, o mesmo professor Brichet anota mal para o progresso e o esforço, e acrescenta, na coluna das observações: "aluno fraco", "sem qualquer mérito”, “muito fraco” (Ibid., p. 198).

Na classe terminale de Filosofia, cursada em 1888-89, o professor Ducatel, de Matemática, anota "passable" para o esforço e o progresso; já o Prof. Aubert, de Física e Química, anota "mal" para o segundo trimestre, e acrescenta: "Não faz absolutamente nada” (Ibid., p. 250).

Ao final do ensino secundário, Marcel Proust foi aprovado no exame baccalauréat. Após alguns meses de serviço militar, ingressou na École libre des Sciences Politiques em 1890, onde frequentou a seção diplomática, e na Faculdade de Direito, no ano seguinte. Obteve a Licença em Direito em 1893 e a licence es lettre en philosophie em 1895 (Tadié, 1996).

A matemática, portanto, não foi objeto de estudos posteriores ao liceu. Importante ainda é registrar que, se Proust frequentou o ensino secundário clássico, humanista e literário, a escrita do romance é posterior à reforma de 1902 e ao debate produzido em torno dela.

\section{Evocações dos tempos de escola pelo narrador de $A$ ì $l a$ Recherche du Temps Perdu}

Nos primeiros volumes do romance, "Du côté de chez Swann" [No caminho de Swann] e "À l'ombre des jeunes filles en fleurs" [À sombra das raparigas em flor], o narrador Marcel fala das reminiscências de sua infância e adolescência. O tempo lembrado é o das férias escolares, vividas na pequena cidade de Combray e no balneário de Balbec, mas também o das férias vividas por antecipação, em Balbec, Florença e Veneza.

A escola é imaginada como punição e interdição - das férias e do convívio com a mãe, a mãe cuja ausência, mesmo que por uma noite, provocava tanto sofrimento:

Je savais que le cas dans lequel je me mettais était de tous celui qui pouvait avoir pour moi, de la part de mes parents, les conséquences les plus graves, bien plus graves en vérité qu'un étranger n'aurait pu les supposer, de celles qu'il aurait cru que pouvaient produire seules des fautes vraiment honteuses. [...] Quand j'irais me mettre sur le chemin de ma mère au moment où elle monterait se coucher, et qu'elle verrait que j'étais resté levè pour lui redire bonsoir dans le couloir, on ne me laisserait plus rester à la maison, on me mettrait au collège le lendemain, c'était certain. (RTP, p. 36)

Sabia que o caso em que me metia era, dentre todos, o que poderia trazer-me, da parte de meus pais, as consequências mais graves, muito 
mais graves na verdade do que o poderia supor um estranho, consequências de que ele só julgaria possíveis as faltas verdadeiramente vergonhosas. [...] Quando fosse colocar-me no caminho de minha mãe, no momento em que se recolhesse ao quarto, e ela visse que eu ficara levantado para tornar a dar-lhe boa noite no corredor, não mais me deixariam ficar em casa, me mandariam para o colégio no dia seguinte, era certo. (ETP1, p. 38)

A presença na escola é evocada como obrigação. O pensamento estava voltado para o mundo exterior:

Plus tard, quand je fus au collège, chaque fois que pendant les classes, je correspondais, aussitôt que le professeur avait la tête tournée, avec un nouvel ami, ma première question était toujours pour lui demander s'il était déjà allée au thêátre et s'il trouvait que le plus grand acteur était bien Got, le second Delaunay, etc. (RTP, p. 67)

Mais tarde, no colégio, todas as vezes em que, mal o professor voltava a cabeça, comunicava-me com algum novo amigo, a primeira pergunta que lhe fazia era se já fora ao teatro e se não achava que o maior ator era mesmo Got, o segundo Delaunay, etc. (ETP1, p. 77)

O tempo passado na escola é descrito como um tempo de aborrecimento e de espera:

Au collège, à la classe d'une heure, le soleil me faisait languir d'impatience et d'ennui en laissant traîner une lueur dorée jusque sur mon pupitre, comme une invitation à la fête où je ne pourrais arriver avant trois heures, jusqu'au moment où Françoise venait me chercher à la sortie, et où nous acheminions vers les Champs-Elysées par les rues decorées de lumiére, encombrées par la foule, et où les balcons, descellés par le soleil et vapoureux, flottaient devant les maisons comme des nuages d'or. (RTP, p. 325)

No colégio, na aula da uma hora, o sol me fazia morrer de impaciência e tédio, deixando arrastar-se um dourado clarão até minha carteira, como um convite à festa aonde eu não poderia chegar antes das três horas, quando Françoise viesse buscar-me à saída e nos encaminhássemos para os Campos Elísios, pelas ruas decoradas de luz, atopetadas de povo, e onde as sacadas vaporosas, varadas pelo sol, flutuavam diante das casas como nuvens de ouro. (ETP1, p. 389)

Sem discursar sobre a escola, o narrador adverte o leitor de que não era um aluno de desempenho brilhante: 
"Est-ce qu'il ne pourrait pas venir une fois prendre a cup of tea, comme disent nos voisins les Anglais" [...] "Mais non, c'est impossible, dit mon oncle, en haussant les épaules, il est très tenu, il travaille beaucoup. Il a tous les prix à son cours", ajouta-t-il, à voix basse pour que je n'entende pas ce mensonge et que je n'y contredise pas. (RTP, p. 70-71).

"Será que ele não poderia vir uma vez tomar a cup of tea, como dizem os nossos vizinhos ingleses?" [...] "Não, não, é impossível”, disse meu tio, erguendo os ombros, "ele é um menino aplicado, estuda muito, tem obtido todos os prêmios no colégio”, acrescentou em voz baixa, para que eu não ouvisse a mentira e não o contradissesse. (ETP1, p. 81)

Nesse trecho, podemos ler uma ironia do autor em relação às tarefas e à avaliação escolar. Pois o tio diz, a seguir: "Quem sabe se não será talvez um pequeno Victor Hugo, uma espécie de Vaulabelle.” Em diversos textos, Proust manifesta sua expectativa de ser lido e reconhecido pela posteridade, e o narrador expressa a mesma expectativa em diferentes trechos do romance. Mas, no seu tempo de escola, era considerado medíocre, e a ideia de que pudesse vir a ser famoso era apenas um artifício do tio, que preferia mantê-lo à distância da amante.

Em diversas passagens, o narrador menciona práticas escolares na composição de metáforas em que faz referência àquilo que é previsível, enfadonho ou repetitivo.

Elle répéta comme une leçon, sur un ton ironique et comme si elle voulait se débarasser de lui: "Je n'ai jamais fait ce genre de choses avec aucune femme." (RTP, p. 290)

Odette repetiu como uma lição, num tom irônico, como se quisesse desembaraçar-se dele: "Eu nunca fiz essa espécie de coisas com nenhuma mulher”. (ETP1, p. 347)

Ce fut sans émotion et comme mettant la dernière ligne à un ennuyeux devoir de classe, que je traçai sur l'enveloppe le nom de Gilberte Swann dont je couvrais jadis mes cahiers pour me donner l'illusion de correspondre avec elle. (RTP, p. 1314)

Foi sem emoção e como quem acrescenta uma última linha a uma aborrecida redação escolar que tracei no envelope o nome de Gilberte Swann de que cobria outrora os meus cadernos para ter a ilusão de corresponder-me com ela. (ETP4, p. 138)

Ces impressions multiples, la mémoire n'est pas capable de nous en fournir immédiatement le souvenir. Mais celui-ci se forme en elle peu à peu et au regard des oeuvres [musicales] qu'on a entendu deux ou trois fois, on est comme le collégien qui a relu à plusieurs reprises avant de 
s'endormir une leçon qu'il croyait ne pas savoir et qui la récite par coeur le lendemain matin. (RTP, p. 422)

A memória é incapaz de fornecer imediatamente a lembrança dessas últimas impressões. Mas essa lembrança se vai formando nela pouco a pouco, e com obras [musicais] ouvidas duas ou três vezes, a gente faz como o colegial que releu várias vezes antes de dormir uma lição que julgava não saber e que recita de cor na manhã seguinte. (ETP2, p. 95)

A partir desses excertos, podemos perceber que, se a escola não ocupa lugar de destaque no romance, isso não se deve a algum esquecimento ou ao tempo da narrativa. Há uma intencionalidade do autor nessas várias referências em que a escola aparece como um lugar em que nada de importante acontece. Se o romance trata sobretudo, como afirma Deleuze (2010), da aprendizagem, essa aprendizagem tem lugar no espaço extra-escolar.

\section{Saberes aritméticos e algébricos na voz do narrador e dos outros personagens}

Se a escola não é tema nem cenário da narrativa, por outro lado o narrador e outros personagens revelam-se, pelos usos de linguagem e pela natureza de seus argumentos, sujeitos escolarizados.

Na voz do Barão de Charlus, a referência a noções da Aritmética parece ser um artifício para expor o pedantismo e a erudição do personagem - representante, no romance, de uma aristocracia que desdenha as aspirações esnobes da burguesia arrivista. No trecho reproduzido a seguir, o Barão comenta com Mme. Verdurin o sucesso da recepção oferecida na casa dela naquela mesma noite, e vangloria-se do seu talento ao compor a lista dos convidados, inclusive ao vetar indicações da anfitriã:

"Il n'y a pas de rien dans une réalisation aussi complète. Tout y concourt. La Duras était merveilleuse. Enfim, tout; c'est pour cela," conclut-il, comme il aimait à morigener, "que je me suis opposé à ce que vous invitiez de ces personnes-diviseurs, qui devant les êtres prépondérants que je vous amenais, eussent joué le rôle de virgules dans une chiffre, et les autres réduites à n'être que de simples dixièmes.” (RTP, p. 1810).

"Não existe nada que não tenha a sua importância numa realização tão completa. Tudo concorre para ela. A Duras estava maravilhosa. Enfim, tudo; foi por isto", concluiu, pois ela gostava de repreender, "que me opus a que a senhora convidasse dessas pessoas-divisores que, perante as personalidades preponderantes que eu pretendia convocar, teriam desempenhado o papel de vírgulas num número, reduzidas as outras a não serem senão simples décimos." (ETP5, p. 254) 
Em vários trechos, dos quais apresentamos alguns ilustrativos, as falas do narrador são reveladoras de uma educação algébrica escolar. Ele usa a expressão “coeficiente" para se referir à mensuração de julgamentos ou emoções, dentre os quais estabelece conexões, como se pudessem compor uma fórmula ou uma equação.

No excerto abaixo, o narrador faz referência a uma medida estimada da distinção social entre Swann e seu pai, segundo a lógica burguesa conservadora de seus avós:

On savait quelles avaient été les fréquentations de son pére, on savait donc quelles étaient les siennes, avec quelles personnes il était "en situation” de frayer. [...] Si l'on avait voulu à toute force appliquer à Swann un coefficient social qui lui fût personnel, entre les autres fils d'agents de situation égale à celle de ses parents, ce coefficient eût été pour lui um peu inférieur parce que, très simple de façons et ayant toujours eu une "toquade" d'objets anciens et de peinture, il demeurait maintenant dans um vieil hôtel où il entassait ses collections et que ma grand-mère rêvait de visiter, mais qui était situé quai d'Orléans, quartier que ma grand-tante trouvait infamant d'habiter. (RTP, p. 23)

Sabia-se quais tinham sido as relações de seu pai; sabia-se, pois, quais eram as suas, com que pessoas estava "em situação" de privar. [...] Se a todo custo se lhe quisesse aplicar um coeficiente social adequado, dentre os demais filhos de corretores de situação igual a de seus pais, tal coeficiente não seria dos mais altos, pois Swann, que era muito simples de trato e sempre tivera a "mania" de antiguidades e pintura, morava agora em uma velha casa onde acumulava suas coleções e que minha avó sonhava visitar, mas que ficava no cais de Orléans, lugar em que era infamante residir, na opinião de minha tia-avó. (ETP1, p. 22)

Em outro trecho, o narrador usa a mesma expressão "coeficiente" para comparar seus sentimentos em relação a Albertine, em dois momentos distintos:

Oui, tous mes désirs m'aidaient dans une certaine mesure à comprendre les siens; c'était déjà une grande souffrance où tous les désirs, plus ils avaient été vifs, étaient changés en tourments d'autant plus cruels; comme si dans cette algébre de la sensibilité ils reparaissaient avec le même coefficient mais avec le signe moins au lieu du signe plus. (RTP, p. 1993)

Sim, todos os meus desejos me ajudavam a compreender, em certa medida, os seus; e era um grande sofrimento, em que todos os desejos, quanto mais vivos tinham sido, se convertiam em tormentos tanto mais cruéis, como se nessa álgebra da sensibilidade reaparecessem com o mesmo coeficiente, mas com o sinal menos em lugar do sinal mais. (ETP6, p. 94) 
A menção às razões direta e inversa evoca o estudo das grandezas direta ou inversamente proporcionais, um tema clássico da Álgebra escolar, e compõe um artifício usado pelo narrador para explicitar sua visão ácida acerca das pretensões intelectuais e artísticas dos salões parisienses de então:

Bien que les mérites spirituels d'un salon et son élégance soient généralement en rapports inverses plutôt que directs, il faut croire, puisque Swann trouvait Mme Bontemps agréable, que toute déchéance acceptée a pour conséquence de rendre les gens moins difficiles sur ceux avec qui ils sont renseignés à se plaire, moins difficiles sur leur esprit comme sur le reste. ( $\mathrm{RTP}, \mathrm{p} .480)$

Embora os méritos espirituais de um salão e sua elegância geralmente estejam em razão antes inversa que direta, é de acreditar, visto que Swann achava a sra. Bontemps agradável, que toda decadência aceita tem como resultado tornar as pessoas menos exigentes no tocante àqueles com quem se resignaram a conviver, menos exigentes quanto ao seu espírito como quanto ao resto. (ETP2, p. 162)

Ainda na voz do narrador, vemos a ideia da extração da "raiz quadrada do termo desconhecido”, que não faz sentido do ponto de vista algébrico, mas evoca a sedução provocada por aquilo que não sabemos decifrar, ou que nos desafia a decifrá-lo, e logo se mostra imerecedor desse esforço:

Mais j'avais depuis longtemps cessé de chercher à extraire d'une femme comme la racine carrée de son inconnu, lequel ne résistait pas souvent à une simple présentation. (RTP, p. 480)

Mas desde muito havia eu cessado de procurar extrair de uma mulher como que a raiz quadrada do seu incógnito, o qual muita vez não resistia a uma simples apresentação. (ETP4, p. 152)

Esses excertos podem ser interpretados como ironia do narrador, que lembra da escola com enfado, e que se permite brincar e construir figuras literárias a partir de tarefas e lições que tanto o tinham aborrecido no passado. Mas também podem ser lidos como ironia face às tendências positivistas da época, que pretendiam apreender a realidade a partir de uma suposta objetividade científica.

A crítica ao conhecimento ancorado em números é mais claramente insinuada no trecho em que o narrador ensaia "calcular" o interesse afetivo de Gilberte:

Je tâchais même d'être "objectif" et pour cela de bien tenir compte de la disproportion qui existait entre l'importance qu'avait pour moi Gilberte et celle non seulement quej'avais pour elle, mais qu'elle même avait pour 
les autres êtres que moi, disproportion qui si je l'eusse omise eût risqué de me faire prendre une simple amabilité de mon amie pour un aveu passionné, une démarche grotesque et avilissante de ma part pour le simple et gracieux mouvement qui vous dirige vers de beaux yeux. [...] Je tâchais de trouver entre ces deux optiques également déformantes celle qui me donnerait la vision juste des choses; les calculs qu'il me fallait faire pour cela me distrayaient un peu de ma souffrance; et soit par obéissance à la réponse des nombres, soit que je leur eusse fait dire ce que je désirais, je me décidai le lendemain d'aller chez les Swann. (RTP, p. 466)

Procurava até ser "objetivo" e, para isso, levar na devida conta a desproporção existente entre a importância que tinha Gilberte para mim e, não só a que eu tinha para ela, mas também a que ela própria tinha para as outras criaturas que não fossem eu, desproporção que, se omitida, poderia fazer-me tomar uma simples amabilidade de minha amiga por uma apaixonada confissão e um passo grotesco e aviltante da minha parte pelo simples e gracioso movimento que nos dirige para uns belos olhos. [...] Tratava de encontrar entre essas duas perspectivas igualmente deformantes aquela que me daria a justa visão das coisas; os cálculos que tinha de fazer para isso me distraíam um pouco de meu sofrimento; e, ou por obediência à resposta dos números, ou por tê-los obrigado a dizer o que eu desejava, resolvi no dia seguinte ir à casa dos Swann. (ETP2, p. 145)

Já ao retratar o interesse do Barão de Charlus pelo Marquês de Surgis, o narrador refere-se à Álgebra com um certo encantamento. Nesse caso, já não se trata de manipular ou produzir números, mas de decifrar um problema:

Non seulement comme une Pythie sur son trépied les yeux lui sortaient de la tête, mais pour que rien ne vînt le distraire de travaux qui exigeaient la cessation des mouvements les plus simples, il avait (pareil à un calculateur qui ne veut rien faire d'autre tant qu'il n'a pas résolu son problème) posé auprès de lui le cigare qu'il avait un peu auparavant dans la bouche et qu'il n'avait plus la liberté d'esprit nécessaire pour fumer. [...] Or, la figure à laquelle $M$. de Charlus appliquait et avec une telle contention toutes ses facultés spirituelles et qui n'était pas à vrai dire de celles qu'on étudie d'habitude more geometrico, c'était celle que lui proposaient les lignes de la figure du jeune marquis de Surgis; elle semblait, tant M. de Charlus était profondément absorbé devant elle, être quelque mot en losange, quelque devinette, quelque problème d'algèbre dont il eût cherché à percer l'énigme ou à dégager la formule. (RTP, p. 1276-1277).

Não só os olhos lhe saíam das órbitas, como a uma Pítia na sua trípode, mas, para que nada o distraísse do seu trabalho, que exigia a cessação dos mais simples movimentos, ele (semelhante a um calculador que não quer fazer nenhuma outra coisa enquanto não resolveu o seu problema) 
pousara perto de si o charuto que pouco antes tinha na boca e que não tinha agora a necessária liberdade de espírito para fumar. [...] Ora, a figura a que o sr. De Charlus aplicava, e com tamanha contensão, todas as suas faculdades espirituais e que a falar verdade não era das que habitualmente se estudam more geometrico, era a que lhe propunham as faces do jovem marquês de Surgis; parecia, tão profundamente absorto estava diante dela o barão de Charlus, alguma frase cifrada, alguma adivinha, algum problema de álgebra de que procurava desvendar o enigma ou descobrir a fórmula. (ETP4, p. 93)

\section{As Geometrias de Proust}

Referências à educação geométrica escolar também estão presentes em vários trechos do romance.

Nas evocações de lugares frequentados na infância, como a casa da tia-avó Léonie ou a igreja da pequena cidade de Combray, as descrições de paisagens, prédios e objetos, inspiradas em John Ruskin ${ }^{9}$, assemelham-se às pinturas impressionistas. Os detalhes que importam, nas descrições, são aqueles evocados pela memória afetiva.

Nomes escolares de figuras geométricas, como o tronco de pirâmide, ou o sólido de revolução, são componentes de metáforas imprecisas, que lhes emprestam novos significados:

C'est ainsi que, pendant longtemps, quand, reveillé la nuit, je me ressouvenais de Combray, je n'en revis jamais que cette sorte de pan lumineux, découpé au milieu d'indistinctes ténèbres, pareil à ceux que l'embrasement d'un feu de Bengale ou quelque projection éléctrique éclairent et sectionnent dans un édifice dont les autres parties restent plongés dans la nuit: à la base assez large, le petit salon, la salle à manger, l'amorce de l'allée obscure par où arriverait M. Swann, l'auteur inconscient de mes tristesses, le vestibule où je m'acheminais vers la première marche de l'escalier, si cruel à monter, qui constituait à lui seul le tronc fort étroit de cette pyramide irregulière; et, au faîte, ma chambre à coucher avec le petir couloir à porte vitrée pour l'entrée de maman. (RTP, p. 43-44)

Assim, por muito tempo, quando despertava de noite e me vinha a recordação de Combray, nunca pude ver mais que aquela espécie de lanço luminoso, recortado no meio de trevas indistintas, semelhante aos que o acender de um fogo de artifício ou alguma projeção elétrica alumiam e secionam em um edifício cujas partes restantes permanecem mergulhadas dentro da noite: na base, bastante larga, o pequeno

$9 \quad$ A respeito de Ruskin e Proust, ver Bastianelli (2015). 
salão, a sala de jantar, o trilho da alameda escura por onde chegaria o sr. Swann, inconsciente autor das minhas tristezas, o vestíbulo de onde me encaminhava para o primeiro degrau da escada, tão cruel de subir, que constituía por si só o tronco, muito estreito, daquela pirâmide irregular; e, no cimo, meu quarto, com o pequeno corredor de porta envidraçada por onde entrava mamãe. (ETP1, p. 47-48)

[...] aucune d'elles ne tient sous sa dépendance toute une partie profonde de ma vie, comme fait le souvenir de ces aspects du clocher de Combray dans les rues qui sont derrière l'église. Qu'on le vît à cinq heures, quand on allait chercher les lettres à la poste, à quelques maison de soi, à gauche, surélevant brusquement d'une cime isolée la ligne de faîte des toits; que si, au contraire, on voulait entrer demander des nouvelles de Mme Sazerat, on suivît des yeux cettes ligne redevenue basse après la descente de son autre versant en sachant qu'il faudrait tourner à la deuxième rue après le clocher; soit qu'encore, poussant plus loin, si on allait à la gare, on le vit obliquement, montrant de profil des arêtes et des sourfaces nouvelles comme un solide surpris à un moment inconnu de sa révolution. (RTP, p. 61)

[...] nenhuma delas domina toda uma parte profunda de minha vida como a lembrança daqueles aspectos do campanário de Combray nas ruas que ficam atrás da igreja. Se algumas vezes ao ir buscar às cinco horas as cartas no correio, a gente o avistava, a algumas casas da nossa, à esquerda, erguendo bruscamente, de um cimo isolado, a linha das cumeeiras; se outras vezes, ao ir saber notícias da sra. Sazerat, vendo que era preciso dobrar a segunda rua após o campanário, seguia-se com os olhos a mesma linha que, depois de haver-se elevado, tornava a baixar em sua outra vertente; se outras vezes ainda seguíamos além, a caminho da estação, e o víamos obliquamente, mostrando de perfil arestas e superfícies novas, como um sólido surpreendido em um desconhecido momento de sua revolução; [...] era sempre a ele que cumpria voltar, a ele, que dominava tudo, admoestando as casas de um imprevisto píncaro, erguido diante de mim como o dedo de Deus, cujo corpo estivesse oculto na multidão dos humanos, sem que por isso eu o confundisse com ela. (ETP1, p. 69)

Entretanto, o raciocínio geométrico, ao qual era atribuído, no ensino secundário clássico, o caráter de disciplinamento do pensamento dedutivo, é em diferentes trechos, ridicularizado pelo narrador, como simplista ou obtuso.

O autor descreve como "espírito de geometria” um raciocínio em que conclusões enganosas são obtidas a partir de premissas falsas ou insuficientes:

Une Courvoisier dont le père avait été ministre de l'Empereur, ayant à donner une matinée en honneur de la princesse Mathilde, déduisit par 
esprit de géometrie qu'elle ne pouvait inviter que des bonapartistes. (RTP, p. 1106)

Uma Courvoisier cujo pai fora ministro do Imperador e que tinha de dar uma matinée em honra da princesa Matilde, deduziu por espírito de geometria que só poderia convidar a bonapartistas. (ETP3, p. 420)

Na mesma linha, a ideia do “teorema irrefutável” aparece em alusão aos raciocínios que se pretendem completos, definitivos, e que evitam interrogações acerca de seus pressupostos:

M. Reinach manoeuvrait par le sentiment des gens qui ne l'avaient jamais vu, alors que pour lui l'affaire Dreyfus se posait seulement devant sa raison comme un théoreme irréfutable et qu'il "démontra en effet", par la plus étonnante réussite de politique rationelle (réussite contre la France, dirent certains) qu'on ait jamais vue. [...] Peut-être ce rationaliste manoeuvreur de foules était-il lui-même manoeuvré par son ascendance. (RTP, p. 973).

O sr. Reinach manobrava pelo sentimento pessoas que jamais o tinham visto, quando para ele a questão Dreyfus se lhe apresentava ante a razão apenas como um teorema irrefutável e que ele demonstrou, efetivamente, com a mais surpreendente vitória política racional (vitória contra a França, disseram alguns) que jamais se viu. [...] Talvez esse racionalista manobrador de multidões fosse ele mesmo manobrado por sua ascendência. (ETP3, p. 266)

A essa Geometria de raciocínios previsíveis, sem referência na experiência sensível e sem lugar para a imaginação, o narrador contrapõe as “verdadeiras” Geometrias: a do rosto da mulher amada, a dos lugares evocados pela memória ou pela imaginação:

Même à un simple point de vue réaliste, les pays que nous désirons tiennent à chaque moment beaucoup plus de place dans notre vie véritable, que les pays où nous nous trouvons effectivement. [...] je sentis que c'était vers la semaine qui commençait le lundi où la blanchisseuse devait rapporter le gilet blanc que j'avais couvert d'encre, que se dirigeaient pour s'y absorber au sortir du temps idéal où elles n'existaient pas encore, les deux Cités Reines dont j'allais avoir, par la plus émouvante des géométries, à inscrire les dômes et les tours dans le plan de ma propre vie. (RTP, p. 314, 316).

Mesmo sob um simples ponto de vista realista, as terras que desejamos ocupam a cada momento muito mais espaço em nossa vida verdadeira do que a terra onde efetivamente nos achamos. [...] senti que era para 
a semana a iniciar-se na segunda em que a lavadeira devia trazer o colete branco que eu manchara de tinta, que se dirigiam, a fim de ali se absorverem, ao sair do tempo ideal onde ainda não existiam, aquelas duas Cidades Rainhas cujos domos e torres eu ia inscrever, na mais emocionante das geometrias, dentro do plano da minha própria vida. (ETP1, p. 375, 378)

Car cette photographie c'était comme une rencontre de plus ajoutée à celles que j'avais déjà faites de Mme de Guermantes; bien mieux, une rencontre prolongée, comme si, par un brusque progrès dans nos relations, elle s'était arretée auprès de moi, en chapeau de jardin, et m'avait laissé pour la premiére fois regarder à loisir ce gras de joue, ce tournant de nuque, ce coin de sourcils (jusqu'ici voilés pour moi par la rapidité de son passage, l'étourdissement de mes impressions, l'inconsistance du souvenir); et leur contemplation, autant que celle de la gorge et des bras d'une femme que je n'aurais jamais vue qu'en robe montante, m'était une voluptueuse découverte, une faveur. Ces lignes qu'il me semblait presque défendu de regarder, je pourrais les étudier là comme dans un traité de la seule géometrie qui eût de la valeur pour moi. [RTP, p. 806-807]

Pois aquela fotografia era como um encontro a mais, dos que eu já tivera com a sra. de Guermantes, melhor ainda, um encontro prolongado, como se, por um súbito progresso em nossas relações, ela se detivesse a meu lado, de chapéu de jardim, me deixasse olhar detidamente pela primeira vez aquela polpa de face, aquela curva de nuca, aquele ângulo de sobrancelhas (até então velados para mim pela rapidez de sua passagem, o aturdimento das minhas impressões, a inconstância da recordação); e sua contemplação, tanto como a do colo e braços de uma mulher que eu nunca tivesse visto a não ser de vestido afogado, me era uma voluptuosa descoberta, um grande favor. Aquelas linhas que me parecia quase proibido olhar, poderia estudá-las ali como num tratado da única geometria que tinha valor para mim. (ETP3, p. 71)

Mais comme compensation d'une progression si familière, on a les tâtonnements mêmes du chauffeur incertain de sa route et revenant sur ses pas, les chassés-croisés de la perspective faisant jouer un château aux quatre coins avec une colline, une église et la mer, pendant qu'on se rapproche de lui, bien qu'il se blottisse vainement sous sa feuillée séculaire; ces cercles de plus en plus rapprochés que décrit l'automobile autour d'une ville fascinée qui fuyait dans tous les sens pour lui échapper et sur laquelle finalement il fonce tout droit, à pic, au fond de la vallée, où elle reste gisante à terre; de sorte que cet emplacement, point unique que l'automobile semble avoir dépouillé du mystère des trains express, il donne par contre l'impression de le découvrir, de le déterminer nousmême comme avec un compas, de nous aider à sentir d'une main plus amoureusement exploratrice, avec une plus fine précision, la véritable géométrie, la belle 'mesure de la terre’. (RTP, p. 1512) 
Mas como para compensar uma progressão tão familiar, tem a gente os próprios tenteios do chofer incerto do caminho e que retrocede, pois os ziguezagues da perspectiva fazem com que um castelo brinque de esconder com uma colina, uma igreja e o mar, enquanto dele nos aproximamos, embora embalde se encolha sob a sua folhagem secular, esses círculos cada vez mais próximos que descrevia o automóvel em torno de uma cidade fascinada que fugia em todas as direções, para escapar, e sobre a qual ele avança direito, a pique, até o fundo do vale onde ela jaz por terra; de maneira que essa localização, ponto único, que o automóvel parece haver despojado do mistério dos trens expressos, dá pelo contrário, a impressão de o descobrirmos, de o determinarmos nós mesmos com um compasso, de nos ajudar a sentir com mão mais amorosamente exploradora, com mais fina precisão, a verdadeira geometria, a bela medida da terra. (ETP4, p. 386)

\section{Considerações finais}

Se a escola é, no discurso do narrador, um lugar de espera, de acontecimentos repetidos e previsíveis, enquanto a vida, o movimento, as descobertas e tudo que é relevante ocorre do lado de fora, o texto é carregado de indícios de que o autor é não apenas um sujeito escolarizado, mas um aluno mais atento do que imaginaram seus professores de Matemática.

Palavras que um dia compuseram lições de Álgebra e de Geometria são mobilizadas, engenhosamente, na composição de metáforas, na construção dos personagens e de seus usos de linguagem, como recursos estéticos na composição de paisagens imaginárias ou nas críticas insinuadas ao pensamento positivista contra o qual Proust se batia. A poeira em que tais noções estavam envoltas é espanada e elas são impregnadas de poesia e de novos significados, diferentes daqueles que tinham nos livros ou nas lições.

Nos anos 1910, tempo da escrita do romance, o Lycée Condorcet era uma instituição viva. Funcionava no mesmo austero prédio do século XVIII, construído para abrigar um convento dos monges capuchinhos, próximo ao Boulevard Haussmann. Mas o ensino secundário clássico, criação do século XIX, já havia sido dissolvido pela reforma de 1902. Do mesmo modo que as carruagens, os vestidos, as recepções lembradas pelo narrador, fazia parte de um tempo perdido - o do passado.

Ainda que discretamente, também a escola é resgatada pelas reminiscências do narrador e pela mão do autor, em um movimento simultâneo de transgressão e de homenagem àquilo que em outros tempos havia sido tema de lições, exercícios e exames.

A leitura da Recherche nos diz que as aulas não foram esquecidas; mas que o que aprendemos e lembramos, daquilo que estudamos na juventude, é reinventado 
pelo olhar e pela memória. A escola está em nós; mas não como nós, um dia, nela estivemos.

\section{Fontes}

Proust, M. (1999). À la recherche du temps perdu. Paris: Gallimard. Texto estabelecido sob a direção de Jean-Yves Tadié.

Proust, M. (1999). Em busca do tempo perdido. No caminho de Swann. v. 1. Porto Alegre: Globo. 20 ed. Tradução de Mario Quintana. Revisão por Olgária Chaim Féres Matos.

Proust, M. (1999). Em busca do tempo perdido. À sombra das raparigas em flor. v. 2. Porto Alegre: Globo. 14 ed. Tradução de Mario Quintana. Revisão por Maria Lúcia Machado.

Proust, M. (1996). Em busca do tempo perdido. O caminho de Guermantes. v. 3. Porto Alegre: Globo. 11 ed. Tradução de Mario Quintana. Revisão por Olgária Chaim Féres Matos.

Proust, M. (1992). Em busca do tempo perdido. Sodoma e Gomorra. v. 4. Porto Alegre: Globo. 11 ed. Tradução de Mario Quintana. Revisão por Olgária Chaim Féres Matos.

Proust, M. (1995). Em busca do tempo perdido. A prisioneira. v. 5. Porto Alegre: Globo. 12 ed. Tradução de Manuel Bandeira e Lourdes Sousa de Alencar. Revisão por Olgária Chaim Féres Matos.

Proust, M. (1999). Em busca do tempo perdido. A fugitiva. v. 6. Porto Alegre: Globo. 11 ed. Tradução de Carlos Drummond de Andrade. Revisão por Olgária Chaim Féres Matos e Pierre Clémens.

Proust, M. (1995). Em busca do tempo perdido. O tempo redescoberto. v. 7. Porto Alegre: Globo. 12 ed. Tradução de Lúcia Miguel Pereira. Revisão por Olgária Chaim Féres Matos.

\section{Referências}

Bastianelli, J. (2015). Ruskin, le prophète de Proust? In J. Bastianelli (Ed.), Marcel Proust John Ruskin (pp. VII-XXXI). Paris: Robert Lafont.

Belhoste, B. (1990). L'enseignement secondaire français et les sciences au début du XXe siècle. La réforme de 1902 des plans d'études et des programmes. Revue d'histoire des sciences, 43(4), 371-400.

Benjamin, W. (2010). Pour l'image de Proust. In W. Benjamin, Sur Proust (pp. 27-42). Caen: Nous.

Caspard, Pierre, Luc, Jean-Noël \& Savoie, Philippe (2005). Lycées, Lycéens, Lycéennes: Deux siècles d'Histoire. Paris: Institut Nacional de Recherche Pédagogique.

Chartier, R. (2011). Defesa e ilustração da noção de representação. Fronteiras, 13(24), 15-29.

Chervel A. (1990). História das disciplinas escolares: reflexões sobre um campo de pesquisa. Teoria E Educação, 2, 177-229. 
Coutinho, C. N. (2005). Lukács, Proust e Kafka: Literatura e sociedade no século XX. Rio de Janeiro: Civilização Brasileira.

Deleuze, G. (2010). Proust et les signes. Paris: Quadrige/PUF.

Ferré, A. (1959). Les années de collège de Marcel Proust. Paris: Gallimard.

Gispert, H. \& Hulin, N. (2000). L'enseignement des mathématiques dans ses liens à d'autres disciplines, une perspective historique. Bulletin de l'Union des professeurs de spéciales, mathématiques, physique, chimie, informatique, 192, 10-15.

Gomes, M. L. M. (2012). Escrita autobiográfica e História da Educação Matemática. Bolema, 26(42A), p. 105-137.

Haiduke, P. R. A. (2009). A modernidade entre o desencanto e a idealização: um diálogo entre história e literatura a partir do romance À la recherche du temps perdu de Marcel Proust. Dissertação de Mestrado em História. Curitiba: Universidade Federal do Paraná. Acesso em 15 de junho de 2015. Disponível em: http://www.humanas. ufpr.br/portal/historiapos/files/2012/04/PauloHaiduk.pdf.

Haiduke, P. R. A. (2013). À la recherche du temps perdu como uma monumentalização da belle époque parisiense. Tese de Doutorado em História. Curitiba: Universidade Federal do Paraná. Acesso em 15 de junho de 2015. Disponível em: http://dspace. c3sl.ufpr.br/dspace/bitstream/handle/1884/33463/R\%20-20T\%20-\%20PAULO\%20 RODRIGO\%20ANDRADE\%20HAIDUKE.pdf? sequence $=1$.

Hulin, N. (2007). L'enseignemet secondaire scientifique em France d'un siècle à l'autre. Paris: Institut Nacional de Recherche Pédagogique.

Jacquet-Francillon, F., D'Enfert, R. \& Loeffel, L. (2010). Une histoire de l'école. Anthologie de l'éducation et de l'enseignement en France XVIII ${ }^{\mathrm{e}}-\mathrm{XX}^{\mathrm{e}}$ siècle. Paris: Retz.

Kahn, P. (2010). Éducation et politique. In F. Jacquet-Francillon, R. d'Enfert \& L. Loeffel. Une histoire de l'école (pp. 53-60). Anthologie de l'éducation et de l'enseignement en France XVIII ${ }^{\mathrm{e}}-\mathrm{XX}{ }^{\mathrm{e}}$ siècle. Paris: Retz.

Lopes, E. M. T. (1998). História da educação e literatura: algumas notas. Educação em Revista, 27, 35-46.

Pesavento, S. J. (2004). História E história cultural. Belo Horizonte: Autêntica.

Pesavento, S. J. (2000). As leituras da memória: a cidade imaginária de um cronista do sul brasileiro (Antônio Âlvares Pereira Coruja e a Porto Alegre do início do século XIX). Anos 90: revista do Programa de Pós-Graduação em História, 14, 47-60.

Tadié, J. (1996). Marcel Proust: biographie. Paris: Gallimard.

Xavier, M. E. S. P. (2008). A educação na literatura do século XIX. Campinas: Alínea.

Submetido em: 14/06/2015

Aprovado em: 17/08/2015 